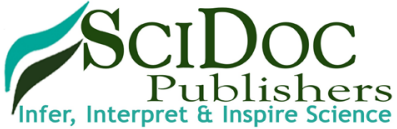

International Journal of Forensic Science \& Pathology (IJFP) ISSN 2332-287X

\title{
Vitreous Humour Lipid Peroxidation as an Emerging Concept of Acute Carbon Monoxide Poisoning
}

Research Article

Agoro ES ${ }^{* *}$, Akubugwo EI ${ }^{1}$, Chinyere $\mathrm{GC}^{1}$, Nwachuku $\mathrm{IE}^{2}$, Agi $\mathrm{VN}^{2}$

${ }^{1}$ The Department Of Biochemistry, State University, Uturu, Abia State, Nigeria.

${ }^{2}$ The Department Of Medical Laboratory Sceicne, Rivers State University Of Science And Technology, Nigeria.

\section{Abstract}

Carbon monoxide (CO) is a euphoric poisonous gas with the predisposition of causing death depending on its concentration. This study was designed to assess the effects of acute CO poisoning on oxidative stress indicators and other ancillary biochemical parameters. Eighteen (18) rabbits divided into three groups of six each constituted the sample size. The groups comprised of controls (CG), disguised death (DD) and CO death (CD). The CO utilized for the study was a product of portable generating set (SUMEC). Vitreous humor was extracted from the eyes of rabbits and assayed for lipid peroxidation parameters such as catalase (CAT), superoxide dismutase (SOD), malonaldehyde (MDA), glutathione reducatase (GT), lipid profiles, uric acids and glucose using standard methods. The result showed that vitreous SOD was significantly lower $(\mathrm{P}<$ 0.05 ) in both the DD and CD, but more markedly lower in the CD. On the contrarily, vitreous CAT was significantly higher $(\mathrm{P}<0.05)$ in the DDs. Also, vitreous MDA exhibited significant increase $(\mathrm{P}<0.05)$ in both the DDs and CDs. Vitreous GT showed no significant difference $(\mathrm{P}>0.05)$. The vitreous lipid profiles result showed a pan markedly significant decrease $(\mathrm{P}<0.05)$ in the CDs as compared to the DDs. Vitreous uric acid exhibited a significant decrease only in the CDs, whereas vitreous glucose decreased both in the DD and CD, but more pronounced in the DD. Therefore, the findings showed that lipid peroxidation is a phenomenon associated with acute carbon monoxide poisoning.

Keywords: Forensic Science; Lipid Peroxidation; Vitreous Humour; Disguised Death (DD); Carbon Monoxide Death (CD).

\section{Background}

Lipid peroxidation refers to the oxidative degeneration of lipids. It is the process in which free radicals "steal" electrons from lipids in cell membranes, resulting in cell damage [1]. It most often affects polyunsaturated fatty acids, because they contain multiple double bonds. Oxidative stress is a condition characterized by elevated levels of intracellular reactive oxygen species (ROS) which are the progenitors of free radicals [2]. Production of peroxides or free radicals could cause damage to components of cell, including proteins, lipids, and DNA [3]. Excessive oxidation of lipids alters the physical properties of cellular membranes and result to covalent modification of proteins and nucleic acids [4].

Carbon monoxide (CO) is classified as an asphyxiant and its mechanism of action is through hypoxia. It starves the cells of oxygen resulting to grave consequences such as morbidity or mortality. Deaths resulting from CO poisoning is on the increase both in developed, developing and under developed nations of the world due to the heavy reliant of $\mathrm{CO}$ producing equipment. The rapidity of $\mathrm{CO}$ in causing death is now patronized by criminals to commit homicide and disguised as accidental or suicide [5-8].

The reference method for the investigation of death due to CO poisoning is solely by autopsy. An autopsy finding by itself has some limitations especially the absence of anatomical derangements or similarities to other related cases. Another handicaps in utilizing autopsy as a final arbiter in the investigation of CO poisoning death is in decomposition or putrefaction. Mummification is another phenomenon that renders autopsy findings irrelevant in the adjudication of justice. These handicaps to an extent do not affect the vitreous humor composition and consistencies.

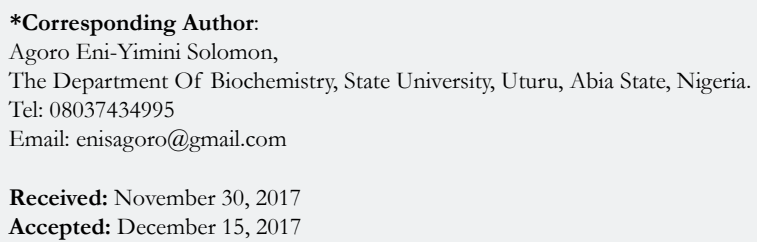

Copyright: Agoro ES ${ }^{\circ}$ 2017. This is an open-access article distributed under the terms of the Creative Commons Attribution License, which permits unrestricted use, distribution and reproduction in any medium, provided the original author and source are credited. 
The use of blood for the assay of oxidative stress markers in postmortem is scientifically unsuitable. Fermentation and putrefaction are proven factors that make blood inappropriate for biochemical analysis after death. These handicaps of blood led us to utilize the vitreous humor as a sample of choice. Vitreous humor is a gelatinous fluid that is void of contaminants and also resistant fermentation even at advanced putrefaction [9]. Also the presence of wide range of biochemicals in the vitreous and its similarities to ante-mortem blood biochemicals make it a preferred sample for postmortem studies [10-12].

In carbon monoxide poisoned patients, an altered balance between reactive oxygen species and antioxidant levels has been reported [13]. Also it has been observed that free radicals and oxidative stress are among factors involved in pathogenesis of acute carbon monoxide poisoning and particularly appear to have a role in carbon monoxide induced cardio-toxicity [14]. Another author also held the view of a strong relationship between acute carbon monoxide poisoning and free radical and oxidative stress [15].

This study utilized arrays of biochemical parameters associated with oxidative stress and lipid peroxidation by measuring the concomitant effect of acute CO poisoning. The parameters include; total cholesterol, triacylglycerol, high density lipoprotein (HDL), low density lipoprotein (LDL) and very low density lipoprotein (VLDL), malonaldehyde (MDA), superoxide dismutase (SOD), catalase, glutathione Reductase (GPR), uric acid and glucose. The study is aimed at critically analyzing the patterns presented by the studied vitreous biochemical parameters in postmortem acute $\mathrm{CO}$ poisoning.

\section{Materials and Methods}

\section{Study Area}

Three locations were used for the study; the intoxication and the laboratory analysis. The intoxication and vitreous extraction were carried out along the Epie Creek axis in IgbogeneEpie of Bayela State. However, the laboratory analysis took place at the Biochemistry Laboratory of the Federal University of Agriculture, Umudike, Abia State and the Chemical Pathology Department of the Niger Delta University Teaching Hospital, Okolobiri, Bayelsa State.

\section{Study Population}

The sample size was calculated based on the formula of Mead's resource equation [16]. Rabbit was selected as the animal of choice for the study due to its phylogenetic relationship to human, coupled with its large eye globe.The research utilized only male albino rabbits of same age and weight (six to eight months and $1.5-2 \mathrm{~kg})$.

A total of eighteen (18) rabbits were used; six (6) rabbits constituted the control group (CG). Treatments one and two were made up of six rabbits each. Treatment one comprised rabbits mechanically sacrificed (suffocation technique) before exposure and termed disguised death (DD). Whereas treatment two was made up of rabbits that died as a result of intoxication with maximum carbon monoxide exposure and termed carbon monoxide death
(CD). The CD rabbits died about two hours into the acute CO intoxication and samples collected within 30 minutes postmortem. The control group was treated in similar manner to the treatment one except for the $\mathrm{CO}$ exposure and the 30 minutes postmortem sample collection. The $\mathrm{CO}$ gas was produced using one stroke generator (SUMEC) and acute concentrations extrapolated from the findings of Golden [17], and Struttmann et al.,[18].

\section{Ethical Approval}

The ethical clearance and experimental protocol were approved by the Ethics Committee of the Bayelsa State Ministry of Health. The Animal Welfare Act of 1985 of the United States of America for research and Institutional Animal Care and Use Committee (IACUC) protocol were stringently adhered to.

\section{Collection of Sample}

Rabbits used were apparently healthy and active as confirmed and approved by a veterinary doctor. The vitreous humor samples were collected by the method of Coe [19]. Adequate care was taken to gently aspirate the fluid to avoid tearing of any loose tissue fragments surrounding the vitreous chamber. On an average 1.0 $\mathrm{mL}$ was collected from each rabbit eye. Only crystal clear liquid free of tissue contaminants and fragments was used in the study.

Immediately after sample collection, the vitreous humour was transferred into plain containers, frozen and dispatched for the required laboratory analysis.

\section{Laboratory Analysis}

Vitreous Catalase (CAT) and Superoxide dismutase (SOD) were estimated according to the methods of Aebi [20] and Xin et al., [21] respectively. Vitreous malondialdehyde (MDA) analysis was done by determining the concentration of MDA formed using the method of Varshney and Kale [22]. The concentration of glutathione was determined according to the method of Habiget al., [23].

Vitreous total cholesterol, triglyceride and HDL were estimated quantitatively using Agappe kit as specified by Agappe Diagnostics (Switzerland) (Agappe Kit Leaflet). Vitreous LDL concentration was derived mathematically by the formula as shown by Carl and Edward [24]. Vitreous VLDL concentration was derived mathematically by the formula as stated by Friedewaldet al., [25]. However, vitreous uric acid was measured quantitatively by Uricase Method as specified by AGAPPE Diagnostics (Switzerland) (Agappe Kit Leaflet). Glucose was estimated using glucose oxidase method.

The concentration of $\mathrm{CO}$ was extrapolated from the findings of Golden [17], and Struttmann et al., [18] in averring CO concentrations (ppm) that can lead to death and its corresponding carboxyhaemoglobin.

\section{Statistical Analyses}

Data were analyzed with Statistical Package for Social Sciences (SPSS) program (SPSS Inc., Chicago, IL, USA; Version 18-21) and Microsoft excel. Pearson correlation analyses were used to establish relationships between studied vitreous oxidative stress bio- 
markers and the acute graded carbon monoxide concentrations. Also, one-way ANOVA (Post Hoc- LSD) was used in comparing the means of the studied parameters of the study groups. Graphical presentation was done using GraphPad prism 5.

\section{Results}

Table 1 shows a multiple comparisons of some vitreous oxidative stress biomarkers (Mean $\pm \mathrm{SD}$ ) in three groups of acute $\mathrm{CO}$ intoxications using one Way-Anova (LSD's post hoc test). Vitreous CAT was strictly significantly higher $(\mathrm{P}<0.05)$ in the DD group. Vitreous MDA was significantly increased $(\mathrm{P}<0.05)$, whereas SOD was significantly lower $(\mathrm{P}<0.05)$ in both the DD and CD groups. However, vitreous GT exhibited non-significant difference $(\mathrm{P}>0.05)$ acrossed the study groups.

Table 2: Showed a correlational analysis between vitreous lipid profiles of the DD and CD groups and the acute graded CO.
Correlation was observed between the vitreous lipid profiles of the DD and acute graded CO, whereas CD was not.

Table 3 shows a multiple comparisons of vitreous glucose anduric acid (Mean \pm SD) of the three groups of acute $\mathrm{CO}$ intoxications using one way-Anova (Post Hoc-LSD). Vitreous uric acid was strictly significantly lower $(\mathrm{P}<0.05)$ in the $\mathrm{CD}$ group. Whereas, vitreous glucose increased significantly $(\mathrm{P}<0.05)$ in the CD group.

\section{Discussion}

Lipid peroxidation is a product of oxidative stress occasioned by the generation of excess free radicals with the attendant production of corresponding antioxidants and buffers [3, 26]. Oxidative stress is the progenitor of lipid peroxidation; excessive oxidation of lipids alters the physical properties of cellular membranes and can cause covalent modification of proteins and nucleic acids [4].

Table 1. A Multiple Comparison of Postmortem Vitreous Oxidative Stress Biomarkers on the basis of Levels of Acute CO Intoxications.

\begin{tabular}{|c|c|c|c|c|c|}
\hline Parameters & Control & DD & CD & F-Value & P-Value \\
\hline GT $(\mu / \mathrm{mg})$ & $21.98 \pm 1.06$ & $21.77 \pm 0.61$ & $23.44 \pm 1.61$ & 2.44 & 0.142 \\
\hline SOD $(\mu / \mathrm{mg})$ & $5.81 \pm 0.23$ & $4.64 \pm 0.19^{*}$ & $4.49 \pm 0.33^{*}$ & 14.689 & 0.001 \\
\hline CAT $(\mu / \mathrm{mg})$ & $62.99 \pm 2.17$ & $66.81 \pm 1.50^{*}$ & $63.26 \pm 3.10$ & 3.299 & 0.084 \\
\hline MDA $(\mathrm{mmol} / \mathrm{mg})$ & $2.44 \pm 0.22$ & $3.56 \pm 0.16^{*}$ & $3.56 \pm 0.79^{*}$ & 7.191 & 0.014 \\
\hline
\end{tabular}

Symbols: $* \mathrm{P}<0.05$ vs control, \#P $<0.05$ vs DD.

Legend: Glutathione Reductase; SOD = Superoxide Dismutase; CAT= Catalase; MDA = Malondialdehyde; DD- Disguised death; CD-Carbon monoxide Death.

Table 2. The Observed Pearson's Correlation Coefficient between Graded Carbon Monoxide Concentrations and Studied Vitreous Postmortem Biochemical Parameters for the DD and CD Groups.

\begin{tabular}{|c|c|c|c|c|}
\hline Parameters Measured & R & Level of Significance & R & Level of Significance \\
\hline & \multicolumn{2}{|c|}{ DD } & \multicolumn{2}{|c|}{ CD } \\
\hline TC (mmol/l) & 0.989 & $0.011^{*}$ & -0.911 & 0.089 \\
\hline TG (mmol/l) & 0.811 & $0.118^{*}$ & -0.435 & 0.565 \\
\hline HDL (mmol/l) & 0.971 & $0.029^{*}$ & -0.867 & 0.133 \\
\hline LDL (mmol/l) & 0.853 & $0.147^{*}$ & -0.834 & 0.166 \\
\hline VLDL (mmol/l) & 0.875 & $0.125^{*}$ & -0.377 & 0.623 \\
\hline
\end{tabular}

\footnotetext{
* Significant,
}

Key: DD $=$ Disguised Death, CD $=$ Carbon Monoxide Death, TC $=$ Total Cholesterol, $\mathrm{TG}=$ Triacylglycerol, HDL $=$ High Density Lipoprotein, LDL = Low Density Lipoprotein, VLDL = Very Low Density Lipoprotein, $\mathrm{R}=$ Pearson Correlation Coefficient.

Table 3. A Multiple Comparison of Postmortem Vitreous Glucose and Uric Acid on the basis of Levels of Acute CO Intoxications.

\begin{tabular}{|c|c|c|c|c|c|}
\hline Parameters & Control & DD & CD & F-Value & P-Value \\
\hline Glucose $(\mathrm{mmol} / \mathrm{L})$ & $5.2 \pm 0.3$ & $1.7 \pm 0.5^{*}$ & $2.6 \pm 0.5^{* \#}$ & 65.557 & 0 \\
\hline Uric Acid $(\mu \mathrm{mol} / \mathrm{L})$ & $57 \pm 6$ & $50 \pm 4$ & $21 \pm 6^{* \#}$ & 48.289 & 0 \\
\hline
\end{tabular}

Symbols: $* \mathrm{P}<0.05$ vs control, \#P $<0.05$ vs DD.

Key: * Significant at $\mathrm{P}<0.05$. 
However, severe oxidative stress can cause cell death and even moderate oxidation can trigger apoptosis, while more intense stresses may cause necrosis [27].

In carbon monoxide poisoned patients, an altered balance between reactive oxygen species and antioxidant levels has been reported [13]. Also it has been observed that free radicals and oxidative stress are among factors involved in pathogenesis of acute carbon monoxide poisoning and particularly appear to have a role in carbon monoxide induced cardio-toxicity [14]. Another author held a strong relationship between acute carbon monoxide poisoning and free radical and oxidative stress [15].

The findings of the research showed a significant increase in concentration of vitreous MDA both in the DD and CD, whereas vitreous SOD significantly decreased in both study groups though more prominent in the $\mathrm{CD}$. Vitreous catalase significantly increased only the DD group, while vitreous GT exhibited no significant difference in both groups (Table 1). However, the result showed a correlation between acute $\mathrm{CO}$ and vitreous GTR, SOD and CAT (Table 2, Figure. 1, 2 \& 3). The vitreous lipid profiles exhibited a pan markedly decreased concentration in the CDs as against the DD (Figure 4-8). Similarly, vitreous uric acid was significantly decreased only in the CD group, whereas vitreous glucose decreased both in the DD and $\mathrm{CD}$, but more prominent in the DD (Table 3).

The patterns of the oxidative stress markers and the lipid profiles showed explicitly that lipid peroxidation is associated with $\mathrm{CO}$ poisoning death. The destructive tendencies of free radicals could be the basis of the pan reduction in vitreous lipid profiles and uric acids as pinpointed in the study. Cumulatively, the findings of this study could be utilized in the investigation of CO death confirmation especially in scenario of decomposition were autopsy is not practicable.

Malondialdehyde results from lipid peroxidation of polyunsaturated fatty acids [28]. The significant increase in vitreous MDA among the DD and CD group could be attributed to both postmortem changes and $\mathrm{CO}$ mechanisms (Table 1). The increase was

Figure 1. Relationship Between Acute CO Intoxication and Vitreous Glutathione Reductase (GRT).

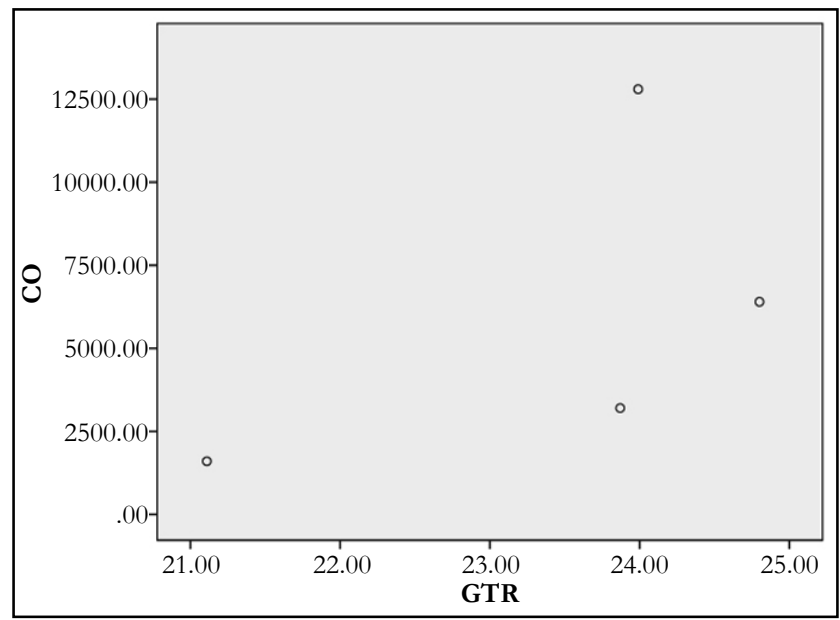

Symbol
$r=$ Pearson Correlation Coefficient $=0.626$
$p=0.374$
$(P>0.05)=$ Significant correlationship

Figure 2. Relationship Between Acute CO Intoxication and Vitreous Superoxide Dismutase (SOD).

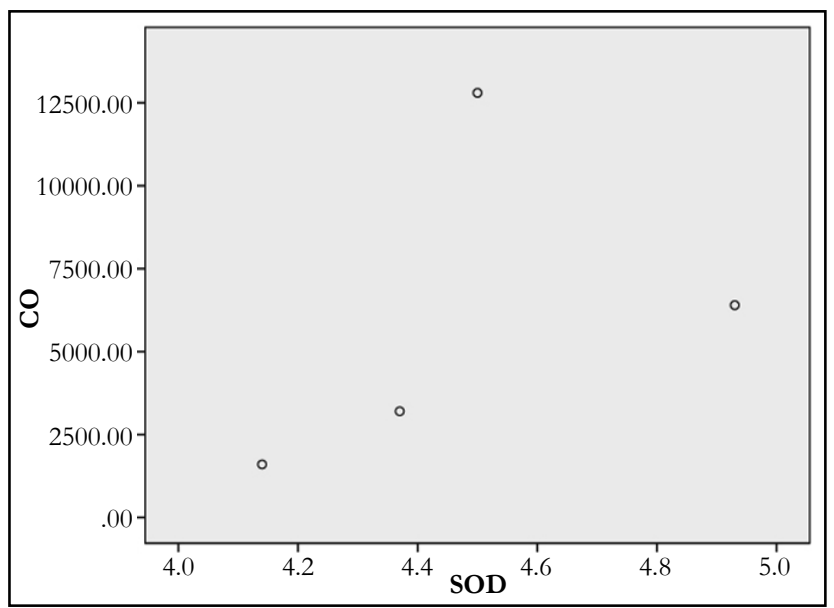

Symbol

$\mathrm{r}=$ Pearson Correlation Coefficient $=0647$

$\mathrm{p}=0.353$

$(\mathrm{P}>0.05)=$ Significant correlationship 
Figure 3. Relationship Between Acute CO Intoxication and Vitreous Catalase (CAT).

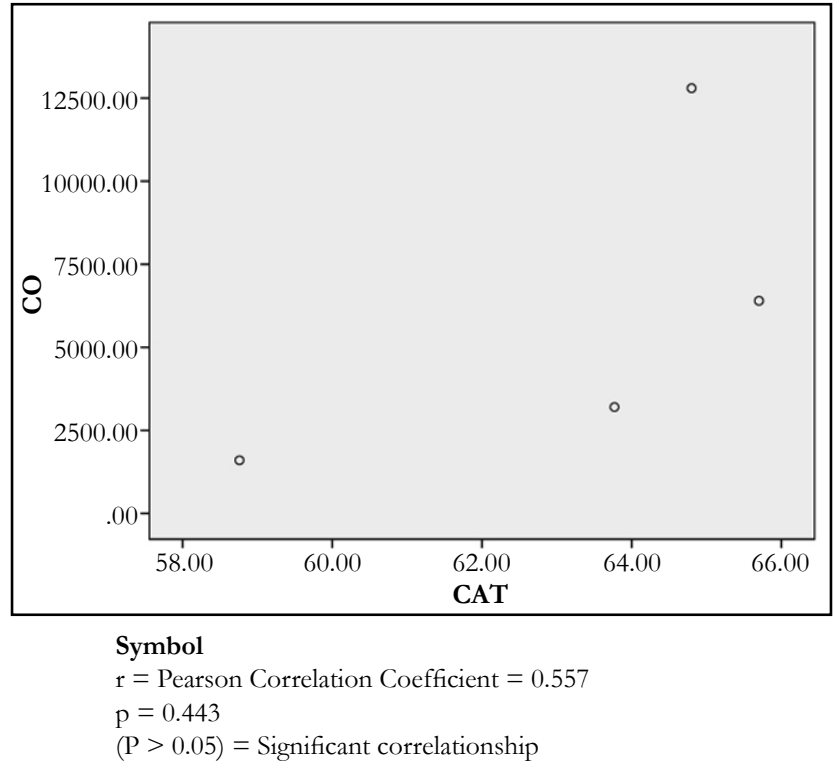

Figure 4. Mean Total Cholesterol Concentration of Rabbit Postmortem Vitreous after Exposure to Acute graded Carbon Monoxide (CO). Significance difference $(p=.00)$ was observed among all groups using LSD.

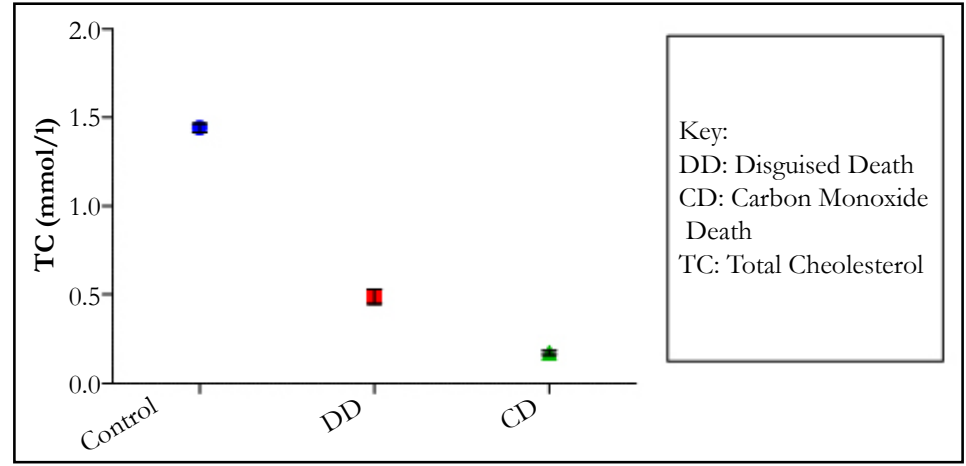

Figure 5. Mean Triglycerides Concentration of Rabbit Postmortem Vitreous after Exposure to Acute graded Carbon Monoxide (CO). Significance difference $(p=.00)$ was observed among all groups using LSD.

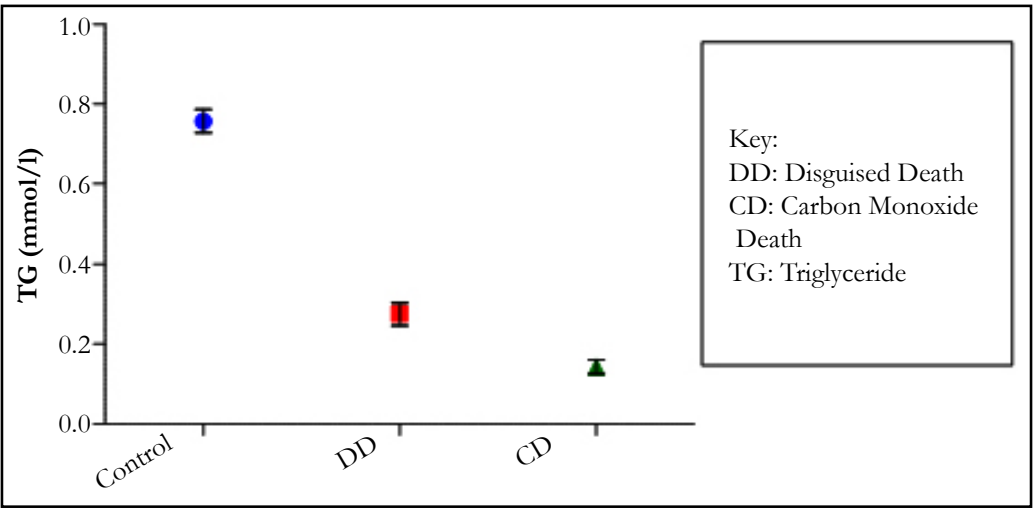

more prominent in the CD group and this could be ascribed to insufficient availability of anti-oxidants utilized for the mopping up of free radicals. The inadequacies observed could be instrumental to lipid peroxidation which is consequently reflected by the pan reduction in lipid profiles. The research supported the findings of Muhammad and Fredrick [29], and Ismail [15] though the severity of exposure could not be ascertained. Contrarily,it contradicted the reports of Miro et al.,[30]; Thom et al., [31] and Guan et al., [32] though with different samples.

Glutathione can act as a scavenger for hydroxyl radicals, singlet oxygen, and various electrophiles [33]. The findings of the study showed a non-significant difference in concentration of vitreous GT both in the DD and CD (Table 1). The findings could be deduced that vitreous GT is not stimulated in the presence of acute grades of $\mathrm{CO}$; hence a non-significant difference in vitreous GT could be used to rule out carbon monoxide poisoning. However, Pearson correlation established a linear relationship between grades of acute CO and vitreous GTR concentrations (Figure 1). This has fortified the above fact that vitreous GTR could serve as veritable tool in detection of acute $\mathrm{CO}$ poisoning. 
Figure 6. Mean High Density Lipoprotein (HDL) Concentration of Rabbit Postmortem Vitreous after Exposure to Acute graded Carbon Monoxide (CO). Significance difference $(p=.00)$ was observed among all groups using LSD.

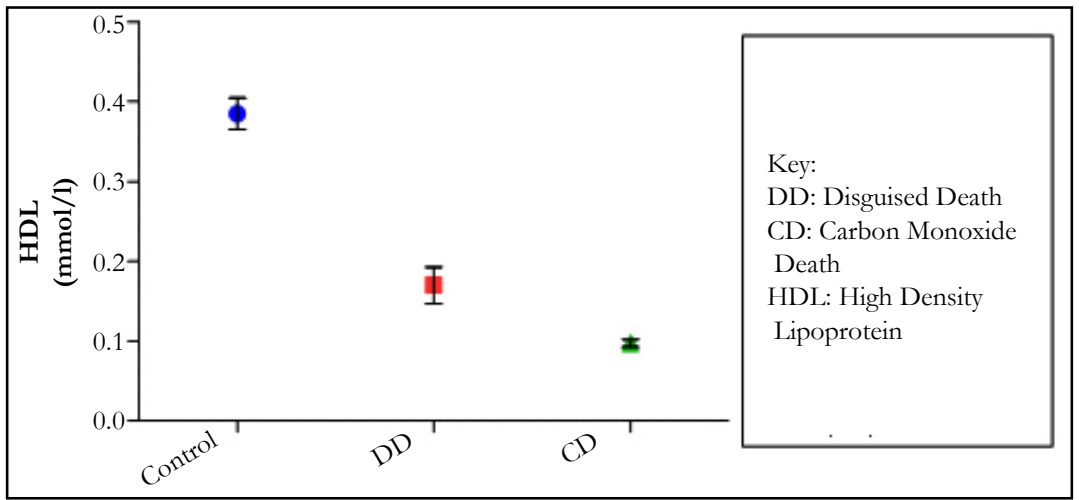

Figure 7. Mean Low Density Lipoprotein (LDL) Concentration of Rabbit Postmortem Vitreous after Exposure to Acute graded Carbon Monoxide (CO). Significance difference $(p=.00)$ was observed among all groups using LSD.

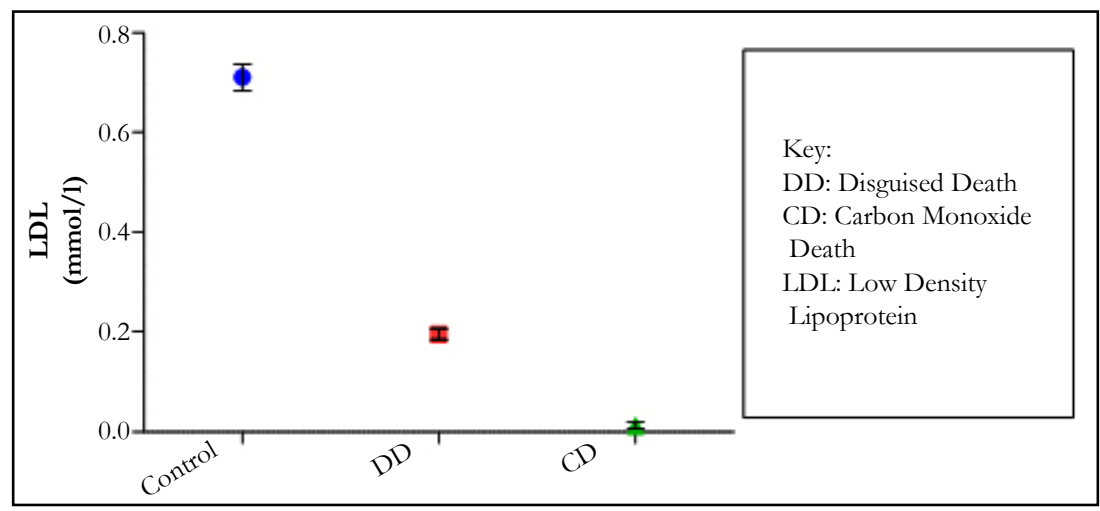

Figure 8. Mean Very Low Density Lipoprotein (VLDL) Concentration of Rabbit Postmortem Vitreous after Exposure to Acute graded Carbon Monoxide (CO). Significance difference $(p=.00)$ was observed among all groups using LSD.

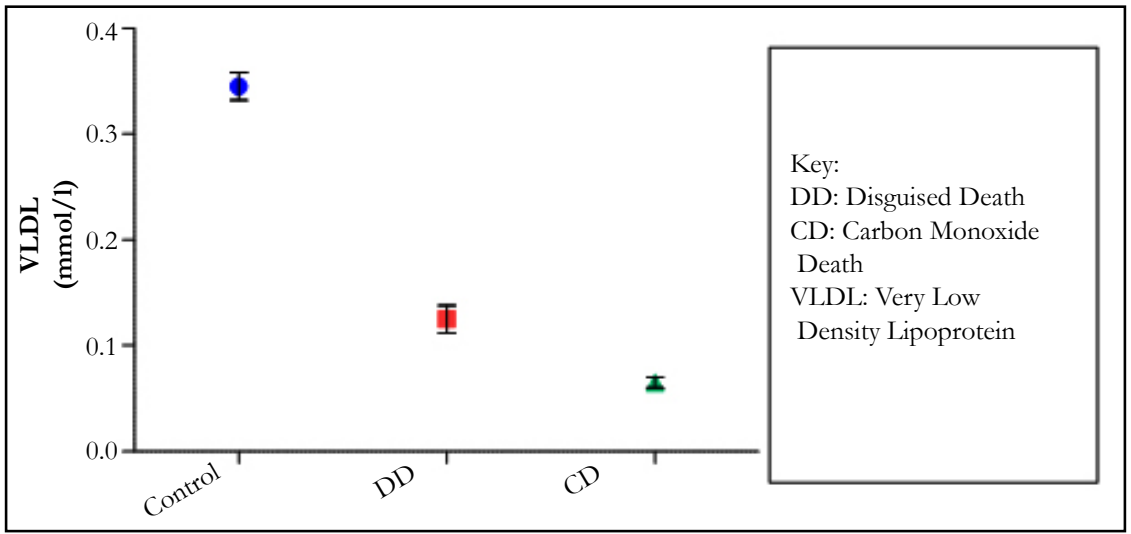

Superoxide is produced as a by-product of oxygen metabolism and, if not regulated, causes many types of cell damage [34]. The research findings established a significant decrease in vitreous SOD observed both in DD and CD (Table 1). This finding depicted that postmortem and acute $\mathrm{CO}$ intoxication are cogent proofs of free radicals generations. The decrease is a product of inadequate anti-oxidants utilized for the buffering of the ravaging free radicals. The mean decrease was more prominent in CD, which is a further affirmation of the heightened free radical generation orchestrated by acute $\mathrm{CO}$ poisoning. The result of the study concur with Ismail et al., [15] and Patel et al., [35] which reported a decrease in concentration of SOD in comparison to the control with a significant negative correlation with $\mathrm{COHb}$ level. However, the result disagreed with the findings of Thom et al., [31]; Webber et al., [36]; Piantaosi et al., [37]; Hamed et al.,[38] and
Kavakli et al.,[13]. The Pearson correlational study also showed a linear relationship between acute grades of CO and vitreous SOD (Figure. 2). This has further supported the relationship between acute $\mathrm{CO}$ and vitreous SOD.

Catalase is a common enzyme found in nearly all living organisms exposed to oxygen (such as bacteria, plants, and animals). It catalyzes the decomposition of hydrogen peroxide to water and oxygen $[39,40]$. The strict significant increase of vitreous catalase only in the DD (Table 1) showed the influence of postmortem change on catalase. Hence, catalases play a significant role in postmortem changes especially decomposition involving breakdown of cells and tissues. The non-significant difference observed in vitreous catalase in the $\mathrm{CD}$ showed explicitly that high concentration of $\mathrm{CO}$ inhibits the mechanism of action of catalase or is 
utilized for the buffering of free radicals, hence the stability seen. Also the observed strict correlation between acute grades of CO and vitreous catalase (Figure 3) also supported the usefulness of vitreous catalase in resolving issues related to acute $\mathrm{CO}$ poisoning. The significant decrease obtained in the lipid profile parameters could be due to inhibition in biosynthesis of lipids or free radical activity leading to lipid peroxidation. This correlates with Chatterjea and Rana [41] observation which attributed decreased lipid profiles by $\mathrm{CO}$ to the blockage of the formation of cholesterol and triglyceride at various stages in the biosynthetic pathways. The decrease in cholesterol and triglyceride resulted to the decrease seen in the lipoproteins.

Free radicals are highly reactive, and capable of damaging almost all types of biomolecules (proteins, lipids, carbohydrate, and nucleic acids). This harmful effect also extends to cells and tissues [42-44]. Hence, the free radicals generated during CO poisoning have the propensity of distorting lipids in the system. It is this effect that cascaded into lipid peroxidation, which in turn reflected the pan reduction in concentration of studied lipid profiles.

Decrease concentration of uric acid could serve as a strict hallmark of acute $\mathrm{CO}$ poisoning and as a promising tool for differentiating $\mathrm{CO}$ death from that of disguised. The enzyme xanthine oxidase catalyzes formation of uric acid from xanthine and hypoxanthine [44]. In humans and higher primates, uric acid is the final oxidation (breakdown) product of purine metabolism and is excreted in urine. In most other mammals, the enzyme uricase further oxidizes uric acid to allantoin [45]. The loss of uricase in higher primates parallels the similar loss of the ability to synthesize ascorbic acid; leading to the suggestion that urate may partially substitute for ascorbate in such species [46]. Both uric acid and ascorbic acid are strong reducing agents (electron donors) and potent antioxidants. Hence the decrease concentration of vitreous uric acid in the CD group could be attributable to the toxicity and hypoxic potentials of CO. Uric acid formation is an enzymatic process which involve arrays of enzymes, hence the inhibition of any of the enyzmes prior to uricase that convert uric acid to allantoin will lead to the decrease in uric acid concentration. The same mechanism of inhibition of the arrays of enzymes in uric acid pathways are used by a lot of drugs (Sevelamer) for renal dysfuction, arthritis and gout management.

Alternatively, the decreased uric acid could be regarded from oxidative stress point of view. Uric acid is a known marker of oxidative stress [41] and may have a potential therapeutic role as an antioxidant [47]. Like other strong reducing substances such as ascorbate, uric acid can also act as aprooxidant. The decrease in vitreous uric acid arises when the concentration of ROS exceeds its buffering capacity. However, the findings of this study contradict that of Baillie et al.,[48] which propose that uric acid is released in hypoxic conditions.

Moreover, the significant decrease of vitreous glucose in all the comparative groups is entirely due to postmortem mechanisms and PMI (Table 3). The research supported the works of Sippel and Mottonen [49], Bray et al.,[50] and Peclet et al.,[51] that showed a decrease in vitreous glucose in postmortem. A rapid decrease in vitreous glucose levels during postmortem period is due to anaerobic degradation or glycolysis. The decrease may be up to $35 \%$ in the first hour to $70 \%$ after 6 h PMI 5 [4]. The whole process of glycolysis is completed by 3.5 to $7 \mathrm{~h}$ after death [52] and is time and temperature dependent [52]. The decline in vitreous glucose in the CD group is not as prominent as in the DD group. The difference could be attributable to the inhibitory role of $\mathrm{CO}$ on the vitreous glucose. Also, the PMI could also be another factor. A further research to establish the inhibitory role of $\mathrm{CO}$ is advocated.

\section{Conclusion}

The study has shown that acute CO poisoning has a proportionate effect on some vitreous biochemical parameters associated with lipid peroxidation. Such parameters include; lipid profiles, MDA, GT, CAT, SOD, uric acid and glucose. These parameters are altered in course of acute CO poisoning and to an extent could be of help in acute $\mathrm{CO}$ poisoning detection and investigation. The findings of this study should be replicated in human subjects so as to enhance its applicability in forensic science.

\section{Acknowledgements}

The authors thank the laboratory staff of the department of chemical pathology of the Niger Delta University Teaching Hospital, Okolobiri Bayelsa State and the Federal Medical Centre, Yenagoa, Bayelsa State for the laboratory analysis. Also, a special appreciation to the EnisBiomedicals (eBm) LTD for the statistical analysis, literature search and type setting of the work.

\section{References}

[1]. David LN, Michael MC. Lehninger Principles of Biochemistry. 4th ed. Sara Tenney; 2005

[2]. Schafer FQ, Buettner GR. Redox environment of the cell as viewed through the redox state of the glutathione disulfide/glutathione couple. Free Radic Biol Med. 2001 Jun 1;30(11):1191-212. PubMed PMID:11368918.

[3]. Chandra K, Salman AS, Mohd A, Sweety R, Ali KN. Protection against FCA induced oxidative stress induced DNA damage as a model of arthritis and In vitro anti-arthritic potential of costus speciosus rhizome extract. Inter J Pharma Phyto Res. 2015;7(2):383-9.

[4]. Michael MG, Brent RS. Lipid peroxidation in cell death. Biochem Biophys Res Commun. 2017 Jan 15;482(3):419-425.PubMed PMID: 28212725.

[5]. Akaishi S, Oshida S, Hiraiwa K, Sebetan IM, Ohno Y, Kuroda F, Suzuki T, et al. Homicide and camouflaged carbon monoxide poisoning in Japan. Z Rechtsmed. 1982;88(4):297-304. PubMed PMID: 7124129.

[6]. Patel P, Sattler S. The Case Files: Carbon Monoxide Intoxication Disguised as Atrial Fibrillation. Emergency Medicine News. 2013 Jun 4;35(6A).

[7]. Aldossary M, Almadni O, Kharoshah M, Alsaif D, Alsowayigh K, Alfaraidy M. Carbon monoxide toxicity in Dammam, KSA: Retrospective study. Egyptian journal of forensic sciences. 2015 Mar 31;5(1):36-8. 8.

[8]. Li F, Chan HC, Liu S, Jia H, Li H, Hu Y, et al. Carbon monoxide poisoning as a cause of death in Wuhan, China: A retrospective six-year epidemiological study (2009-2014). Forensic Sci Int. 2015 Aug;253:112-8. PubMed PMID: 26115227

[9]. Palmiere C, Mangin P. Postmortem chemistry update part 1. Int J Legal Med. 2012 Mar;126(2):187-98. PubMed PMID: 21947676.

[10]. Agoro ES, Okoye FB, Onyenekwe CC, Azuonwu O, Ebiere NE. Extrapolation of Three Hourly Post-Mortem Interval using Some Vitreous Chemistry Parameters. J Forensic Res. 2017;8(360):2.

[11]. Agoro ES, Okoye FB, Azuonwu O, Ebiere NE. The Effect of Age and Sex on Vitreous Humour Chemistry and Postmortem Interval (PMI). Indian Journal of Forensic Medicine \& Toxicology. 2017 Jul 1;11(2).

[12]. Agoro ES, Wankasi MM. The Forensic Application of Vitreous Humour Biochemistry in Postmortem Disease Diagnosis. Indian Journal of Forensic Medicine \& Toxicology. 2017 Jan 1;11(1).

[13]. Kavakli HS, Erel O, Delice O, Gormez G, Isikoglu S, Tanriverdi F. Oxidative stress increases in carbon monoxide poisoning patients. Human \& experimental toxicology. $2011 \mathrm{Feb} ; 30(2): 160-4$.

[14]. Wang F, He Q, Sun Y, Dai X, Yang,X.P. Female adult mouse cardiomyocytes are protected against oxidative stress. Hypertension. 2010 May;55(5):11728. PubMed PMID: 20212261. 
[15]. Ismail MM, El-Ghamry H, Shaker OG, Fawzi MM, Ibrahim SF. Some biomarkers in carbon monoxide-induced cardiotoxicity. J Environ Anal Toxicol. 2013;3(176):2161-0525

[16]. Hubrecht RC, Kirkwood J, editors. The UFAW handbook on the care and management of laboratory and other research animals. John Wiley \& Sons; 2010 Jan 19.

[17]. Golden M. Carbon monoxide poisoning. J Emerg Nurs, 2008 Dec;34(6):538-542.

[18]. Struttmann T, Scheerer A, Prince TS, Goldstein LA. Unintentional carbon monoxide poisoning from an unlikely source. The Journal of the American Board of Family Practice. 1998 Nov 1;11(6):481-4.

[19]. Coe JI.Vitreous potassium as a measure of the postmortem interval: an historical review and critical evaluation. Forensic Sci Int.1989 Aug;42(3):20113. PubMed PMID: 2676789.

[20]. Aebi HE.Catalase. In: Bergmeyer HU,editors. Method of Enzymatic analysis. VCH Weinheim: Germany-Deerfield:FL; 1983.p.273-286.

[21]. Xin Z, Waterman DF, Hemken RW, Harmon RJ. Effects of Copper Status on Neutrophil Function, Superoxide Dismutase, and Copper Distribution in Steers1. Journal of Dairy Science. 1991 Sep 1;74(9):3078-85.

[22]. Varshney R, Kale RK.Effect of calmodulin antagonists on radiation induced lipid peroxidation in microsomes. Int J Radiat Biol.1990 Nov;58(5):733-43. PubMed PMID: 1977818.

[23]. Habig WH, Pabst MJ, Jakoby WB. Glutathione S-transferases. The firsenzymatic step in mercapturic acid formation. J Biol Chem.1974 Nov 25;249(22):7130-9. PubMed PMID: 4436300.

[24]. Carl AB, Edward RA. Analytes of Haemoglobin Metabolism-Porphyrin, Iron, and Bilirubin, In Fundamentals of Clinical Chemistry. 5th ed. Saunders: P. 603.

[25]. Friedewald WT, Levy RI, Fredrickson DS. Estimation of the concentration of low-density lipoprotein cholesterol in plasma, without use of the preparative ultracentrifuge. Clin Chem.1972 Jun;18(6):499-502. PubMed PMID: 4337382.

[26]. Apel K, Hirt H. Reactive oxygen species: metabolism, oxidative stress and signal transduction. Annu Rev Plant Biol. 2004;55:373-99. PubMed PMID: 15377225.

[27]. Lennon, S.V., Martin, S.J. and Cotter, T.G. Dose-dependent induction of apoptosis in human tumour cell lines by widely diverging stimuli. Cell Prolif. 1991 Mar;24(2):203-14. PubMed PMID: 2009322

[28]. Davey MW, Stals E, Panis B, Keulemans J, Swennen RL. High-throughput determination of malondialdehyde in plant tissues. Anal Biochem. 2005 Dec 15;347(2):201-7. PubMed PMID: 16289006

[29]. Gwarzo MY, Ujah FO. The Effect of Exhaust Fumes on Glutathione S-Transferase Enzymes in the Lung of Rats Supplemented with Natural Products. British Journal of Pharmacology and Toxicology. 2013 Aug 25;4(4):136-41.

[30]. Miró O, Alonso JR, Casademont J, Jarreta D, Urbano-Márquez A. Oxidative damage on lymphocyte membranes is increased in patients suffering from acute carbon monoxide poisoning. Toxicol Lett. 1999 Nov 22;110(3):21923. PubMed PMID: 10597031.

[31]. Thom SR, Bhopale VM, Han ST, Clark JM, Hardy KR. Intravascular neutrophil activation due to carbon monoxide poisoning. Am J RespirCrit Care Med. 2006 Dec 1;174(11):1239-48. PubMed PMID: 16931637.

[32]. Guan L, ZhangYL, Wen T, Wang XF, Zhu MX. Dynamic changes of heme oxygenase- 1 in the hippocampus of rats after acute carbon monoxide poisoning. Arch Environ ContamToxicol. 2011 Jan;60(1):165-72. PubMed PMID: 20422170
[33]. Champe PC, Harvey RA, Ferrier DR. Biochemistry. 4th ed. Lippincott Williams and Wilkins; 2008

[34]. Hayyan M, Hashim MA, AlNashef I.M. Superoxide Ion: Generation and Chemical Implications, Chem. Rev. 2016 Mar 9;116(5):3029-85. PubMed PMID: 26875845

[35]. Patel AP, Moody AJ, Sneyd JR,Handy RD. Carbon monoxide exposure in rat heart: evidence for two modes of toxicity. BiochemBiophys Res Commun. 2004 Aug 13;321(1):241-6. PubMed PMID: 15358241.

[36]. Webber DS, Lopez I, Korsak RA, Hirota S, Acuna D. Limiting iron availability confers neuroprotection from chronic mild carbon monoxide exposure in the developing auditory system of the rat. J NeurosciRes . 2005 Jun 1;80(5):620-33. PubMed PMID: 15880490.

[37]. Piantadosi CA, Carraway MS, Suliman HB. Carbon monoxide, oxidative stress, and mitochondrial permeability pore transition. Free Radical Biology and Medicine. 2006 Apr 15;40(8):1332-9.

[38]. Hamed S, Brenner B, Aharon A, Daoud D, Roguin, A. Nitric oxide and superoxide dismutase modulate endothelial progenitor cell function in type 2 diabetes mellitus. Cardiovasc Diabetol. 2009 Oct 30;8:56. PubMed PMID: 19878539.

[39]. Chelikani P, Fita I, Loewen PC. Diversity of structures and properties among catalases. Cell Mol Life Sci. 2004 Jan;61(2):192-208. PubMed PMID: 14745498.

[40]. Goodsell DS. Catalase . Molecule of the Month. RCSB PDB-101. 2004 Sep.

[41]. Chatterjea MN, Shinde R.Textbook of Medical Biochemistry.7th ed. Jaypee Brothers; 2007.p.219-224.

[42]. Mayne DP. Clinical Chemistry in Diagnosis and Treatment. 6th ed. ELST; 2002.p.172-188.

[43]. Hille R. Molybdenum-containing hydroxylases. Arch Biochem Biophys. 2005 Jan 1;433(1):107-16. PubMed PMID: 15581570.

[44]. Angstadt CN (Department of Biomedical sciences, Allegheny University of the Health Sciences). Purine and Pyrimidine Metabolism: Purine Catabolism .Net Bio chem. 1997.

[45]. Proctor P.1970. Similar functions of uric acid and ascorbate in man?. Nature. 1970 Nov 28;228(5274):868. PubMed PMID: 5477017

[46]. Becker BF.Towards the physiological function of uric acid. Free Radic Biol Med.1993 Jun;14(6):615-31. PubMed PMID: 8325534

[47]. Glantzounis GK, Tsimoyiannis EC, Kappas AM, Galaris DA.Uric acid and oxidative stress.Current Pharmaceutical Design. Curr Pharm Des. 2005;11(32):4145-51. PubMed PMID: 16375736.

[48]. Baillie JK, Bates MG, Thompson AA, Waring WS, Partridge RW, Schnopp $\mathrm{MF}$, et al. Endogenous urate production augments plasma antioxidant capacity in healthy lowland subjects exposed to high altitude. Chest . 2007 May;131(5):1473-8. PubMed PMID:17494796.

[49]. Sippel H, Mottonen M. Combined glucose and lactate values in vitreous humour for postmortem diagnosis of diabetes mellitus. Forensic Sci Int. 1982 May-Jun;19(3):217-22. PubMed PMID: 7076064.

[50]. Bray M, Luke JL, Blackbourne B.D. Vitreous humor chemistry in deaths associated with rapid chilling and prolonged freshwater immersion. J Forensic Sci.1983 Jul; 28(3):588-93. PubMed PMID: 6619778.

[51]. Peclet C, Picotte P, Jobin F. The use of vitreous humor levels of glucose, lacticacid and blood levels of acetone to establish antemortem hyperglycemia in diabetics. Forensic Sci Int.1994 Mar;65(1):1-6. PubMed PMID: 8206449.

[52]. Hamilton-Paterson JL, Johnson EW. Post-mortem glycolysis. The Journal of Pathology. 1940 May 1;50(3):473-82. 